\title{
Finding Possibility to Develop Alternative Research Model for Knowledge Sharing System as Web 2.0 Service
}

\author{
Sung Hoon Shin
}

\begin{abstract}
Knowledge sharing systems have some characteristics of Web 2.0 such as openness, freedom, and collective intelligence. So, it cannot be valuable without active use of users. This research approaches both aspect of technology acceptance and self-determination to explain the use of knowledge sharing systems. Through survey about knowledge sharing systems, it is proved that they are complementary approach. Though this research has some limitations, it can provide the basic idea for future research about web 2.0.
\end{abstract}

Index Terms-Knowledge sharing, web 2.0, technology acceptance, self determination.

\section{INTRODUCTION}

In these days, most organizations try to encourage employees to share knowledge through information systems to increase their performance or to create value. It's very ideal if the knowledge sharing systems are used actively and properly by members as individual system users. But, unfortunately, many organizations have trouble with this.

To solve this problem, academic and practical researches have been conducted about individual's behavior of knowledge sharing. They can be approached two different ways. One is technological aspect, and the other is motivational aspect.

The main role of information systems for knowledge sharing is to help people share knowledge through common platforms and electronic storage to make access simpler, encouraging economic reuse of knowledge [1]. In this view, Technology Acceptance Model (TAM) has been considered as a dominant research framework for researchers, who have interest in behavior of individual with information systems. TAM has been acknowledged as a simple but strong model for research about information technology (IT), and various follow-up researches have been done and on going. Context of researches with TAM have been varied.

Past researches related to on-line based IT services have been frequently conducted with TAM. The examples of these are acceptance of general web service [2], on-line shopping [3], internet banking [4], mobile commerce [5], and so on. Most of research context like above, value of IT service is made by service providers, and users are passive.

But, trends of on-line based IT services have been changed, like the concept of web 2.0. The concept of web 2.0 was introduced on October, 2004 by Tim O'relly who is CEO of

Manuscript received November 9, 2013; revised January 10, 2014.

Sung Hoon Shin is with the Sogang University, Seoul, Korea (e-mail: gooms@sogang.ac.kr).
O'reilly Media. Web 2.0 services may allow users to interact and collaborate with each other in a social media dialogue as creators of user-generated content in a virtual community, in contrast to websites where people are limited to the passive viewing of content [6]. In other words, service providers propose the value of services which can be co-created by collaboration between each users.

In this aspect of web 2.0, it's insufficient to explain knowledge sharing with technological view alone. For using on-line based IT services and co-creating values through them, users are given more authority and responsibility. Especially, under situation of knowledge sharing in company, that is expected to additional performance through them. So, it's insufficient to explain this kind of IT services usage with TAM. As mentioned before, the other approach to knowledge sharing is motivational aspect which has probability to supplement technological aspect.

In practice, extrinsic motivation such as monetary rewards is often considered by management. This solution looks like simple and plausible, but some recent researches uncovered that it has dim or even negative effect to knowledge sharing behavior [7]. It is confusing problem for researchers and hands-on workers.

The purpose of this study is to find right approaches for encouraging the use of knowledge sharing systems. First, theories about both technological and motivational aspect were reviewed and found the similarity between them. Second, conceptual model was built by literature review based on theoretical framework. Finally, proposed model was tested and the result was compared with technological or motivational only approach to find implications.

\section{THEORETICAL FRAMEWORK}

\section{A. Theory of Planned Behavior and TAM}

Theory of Planned Behavior(TPB) was proposed by Ajzen. Regarding this theory, behavior of individual is influenced by behavioral intention, and behavioral intention is impacted by function among attitude toward behavior, subjective norm, and perceived behavioral control [8], [9].

Attitude toward behavior is an positive or negative evaluation of individuals with the self-performance of the particular behavior [9]. It is mainly influenced by the accessible behavioral beliefs which connects to various consequences and other attributes.

Subjective norm is an individual's perception about the particular behavior, which is influenced by the judgment of significant others [9]. It is similar concept to social influence which has been assessed by social norm and normative belief. 
The concept of perceived behavioral control is influenced by the concept of self-efficacy which came from Bandura's social cognitive theory. It refers "an individual's perceived ease or difficulty of performing the particular behavior" [9]. These three concepts affect individual's behavioral intention, and real behavior.

TAM was influenced by TPB [10], especially the relation between behavioral intention and attitude toward behavior. "Perceived Usefulness" and "Perceived Ease of Use", which are main construct of TAM, are determinants of attitude in TAM.

\section{B. Self Determination Theory}

Self Determination Theory (SDT) is a theoretical frame work about motivation. SDT proposes various level of motivation, and they can be divided two second-order-level types of motivation, which are autonomous motivation and controlled motivation [11].

As SDT, human has three basic needs for autonomous motivation which are competence, autonomy, and relatedness. And intersection of these three needs can bring self determination motivation [12]. Competence refers that people need to gain mastery of tasks and learn different skills, autonomy refers people need to feel in control of their own behaviors and goals, and relatedness refers people need to experience a sense of belonging and attachment to other people.

\section{Assumption with Comparison between Two Theories}

Both TPB and SDT are psychological approaches to find out core elements which influence to behavior of individuals. They have also similarity that three components influence individuals behavioral change include social influence. For example, there are subjective norm of TPB and relatedness of SDT, and perceived behavioral control of TPB and autonomy of SDT. In practice, some research of integrating TPB and SDT have been tried in some researches [13]. Fig. 1. briefly shows the basic concept of TPB and SDT.

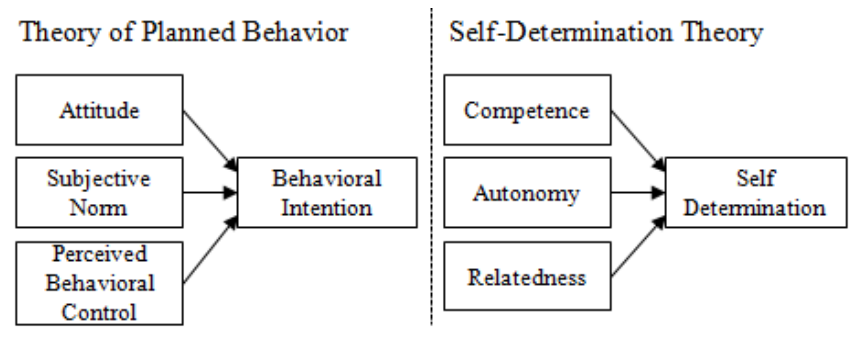

Fig. 1. Basic concept of TPB and SDT.

But as mentioned above, only attitude facet of TPB was considered in TAM. Of course, TAM has been progressed and complicated, but the boundary of theoretical framework is not broaden and it's somewhat lack of explain about web 2.0 services. Therefore, this study tried to develop alternative model with combining two approaches.

\section{LITERATURE REVIEW}

\section{A. Technology Acceptance}

TAM was focused on attitude toward behavior of TPB. It is a basic premise of TAM if individual has an intention to use new technology, and he or she tends to adopt it. And variables about attitude have still most strong influence to behavioral intention, such as "Perceived Usefulness" and "Perceived Ease of Use".

Davis [10] defined that "Perceived Usefulness" is "the degree to which a person believes that using a particular system would enhance his or her job performance", and "Perceived Ease of Use" is "the degree to which a person believes that using a particular system would be free from effort". "Perceived Usefulness" and "Perceived Ease of Use" have direct relation with intention to use, and additionally, "Perceived Ease of Use" has indirect effect to intention to use through "Perceived Usefulness".

Based on TAM, assumption of TAM was included in this research. One different thing is the concept of use. Many researches, based on TAM, were mainly about ready-made technology by service developers or providers, so the role of users were accept or adopt. But the context of this study focused on the knowledge sharing system which needs more active role to users. So, with more active meaning, "Intention to Sharing Knowledge through Information Systems" was used in this research, instead of intent to use.

H1: Perceived Usefulness has a positive effect on Intention to Share Knowledge through Information Systems.

H2: Perceived Ease of Use has a positive effect on Intention to Share Knowledge through Information Systems.

H3: Perceived Ease of Use has a positive effect on Perceived Usefulness.

\section{B. Autonomy}

Gagne [14] proposed that "autonomous motivation will be positively related to intention to share", based on SDT. TPB also proposed personal behavioral control influences to intention. In other research filed like health psychology, "Autonomy" was researched as an important factor to influence to attitude and intention with TPB [15].

On-line based IT services, with the concept of web 2.0, can be valued by autonomous participation of users. So, it can be assumed that people who has high degree of "Autonomy", intends to share knowledge through information systems.

H4: Autonomy has a positive effect on Intention to Share knowledge through Information Systems.

\section{Need for Interaction}

"Need for Interaction" is a concept that was used in various researches about self-service technologies (SSTs). It has been found through many researches that people, who prefer human interaction, has relatively negative attitudes or intention toward SSTs [16], [17] because the purpose of SSTs like internet banking systems is to reduce effort of human resource with same or higher satisfaction of customers.

On the other hand, following TPB and SDT, subjective norm or relatedness positively influences in intention. So, testing "Need for Interaction" in this research is for not only finding the effect of construct itself, but also assuring whether it still has effect on web 2.0 or not.

H5: Need for Interaction has a negative effect on Intention to Share Knowledge through Information Systems.

As SDT, intersection of need for "Autonomy" and 
"Relatedness" can bring self determination motivation. Since "Autonomy" does not mean independent and relationship between individuals affects one's characteristics like self-esteem [18], we can guess there are correlation between "Autonomy" and "Need for Interaction", which is a similar concept of "Relatedness".

H6: Need for Interaction has a positive effect on Autonomy.

As theses hypotheses, the conceptual framework of this research is shown at Fig. 2.

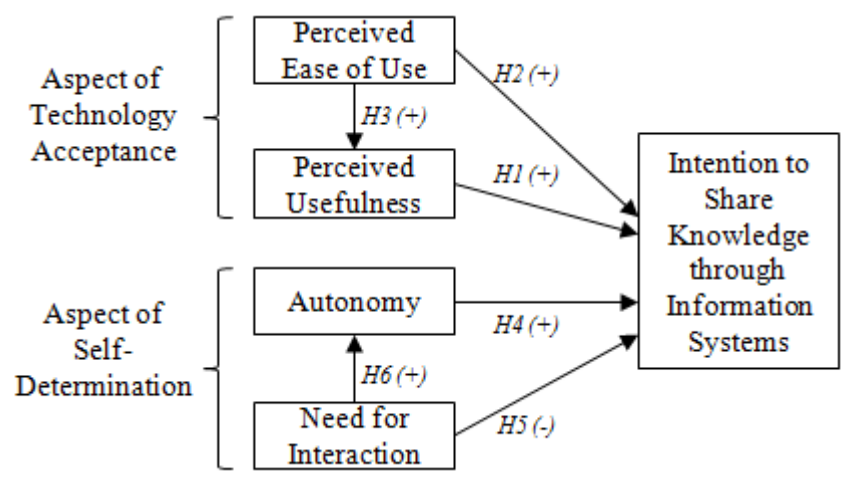

Fig. 2. The conceptual framework of alternative model.

\section{RESEARCH METHODS}

\section{A. Instrument Development and Sampling}

From literature review, constructs and operational definition for each constructs were organized, and it is reported at Table I. Survey for this research contained 22 questionnaires for constructs and 3 questionnaires for demographics such as gender, job experience, and place of work. Data were gathered from employees of one company which has knowledge sharing systems but it's not actively used and has a plan to activate. The company is proper to test difference by place of work, because this company has distributed offices in head quarter and local branch.

TABLE I: OPERATIONAL DEFINITIONS OF CONSTRUCTS

\begin{tabular}{|l|l|}
\hline Constructs & \multicolumn{1}{|c|}{ Operational Definitions } \\
\hline $\begin{array}{l}\text { Perceived } \\
\text { Usefulness }\end{array}$ & $\begin{array}{l}\text { The degree to which a person believes that using a } \\
\text { knowledge sharing system would enhance his or her } \\
\text { job performance [10], [19]. }\end{array}$ \\
\hline $\begin{array}{l}\text { Perceived Ease } \\
\text { of Use }\end{array}$ & $\begin{array}{l}\text { The degree to which a person believes that using a } \\
\text { knowledge sharing system would be free of effort } \\
{[10],[19] .}\end{array}$ \\
\hline Autonomy & $\begin{array}{l}\text { The degree to which the job provides substantial } \\
\text { freedom, independence and discretion in scheduling } \\
\text { the work and in determining the procedures to be } \\
\text { used in carrying it out [20], [21]. }\end{array}$ \\
\hline $\begin{array}{l}\text { Need for } \\
\text { Interaction }\end{array}$ & $\begin{array}{l}\text { The importance of human interaction to the } \\
\text { customer (user) in service (knowledge sharing } \\
\text { system) encounters [16], [22]. }\end{array}$ \\
\hline $\begin{array}{l}\text { Intention to } \\
\text { share knowledge } \\
\text { through IS) }\end{array}$ & $\begin{array}{l}\text { Are assumed to capture the motivational factors that } \\
\text { influence a knowledge sharing behavior [7], [14]. }\end{array}$ \\
\hline
\end{tabular}

Data were gathered from 123 responses. After collecting data, data screening and basic tests were conducted statistically for reliability, validity, and so on. After that, model test and comparison were conducted and the differences by additional variables were compared.

\section{B. Data Analysis}

Among 123 responses, 16 responses were excluded because of missing or invalid data, and doubted whether outliers or not. All of measurement items have goodness of fit which were assessed by $x^{2}$ test, and each item was found that normally distributed through Shapiro-Wilks test. Research sample, which is consisted of 107 respondents, can be differentiated by gender, job experiences, and place of work like Table II.

TABLE II: FREQUENCIES OF SAMPLE CHARACTERISTICS

\begin{tabular}{|l|l|l|l|l|l|}
\hline Gender & \multicolumn{3}{l|}{ Job Experience } & \multicolumn{2}{l|}{ Place of Work } \\
\hline Male & 56 & Under 2 years & 57 & Head office & 67 \\
\hline Female & 51 & Over 2 years & 50 & Branch office & 40 \\
\hline Total & 107 & Total & 107 & Total & 107 \\
\hline
\end{tabular}

\section{Test of Common Method Bias}

In researches about information systems, as a construct more detail, common method bias (CMB) will be decreased [23]. And many other reasons can bring CMB such as common rater effects, item characteristic effects, item context effects, and measurement context effects [24]. Since this research related to information systems, and some construct like "Autonomy" are not unusual construct in information systems research, CMB test was required for this research.

In general, Harman's single factor test, which is based on exploratory factor analysis, is used for testing CMB. Adapting this test with maximum likelihood, responses of this research seems to have no CMB, because they loaded 5 factors with higher than eigenvalue 1 , and rate of first factor loading was not relatively high $(31.936 \%)$.

\section{Test of Reliability and Validity}

To test reliability and validity, Smart-PLS was used in this research. Using partial least square (PLS) method under situation that all of latent variables are linked each other, researchers can see various test results of research model [25].

TABLE III: RESULTS OF RELIABILITY TEST

\begin{tabular}{|l|l|l|l|}
\hline Construct & $\begin{array}{l}\text { Cronbach's } \\
\text { Alpha }\end{array}$ & $\begin{array}{l}\text { Composite } \\
\text { Reliability }\end{array}$ & AVE \\
\hline $\begin{array}{l}\text { Intention to Share } \\
\text { Knowledge through } \\
\text { Information Systems }\end{array}$ & 0.867 & 0.904 & 0.657 \\
\hline Autonomy & 0.681 & 0.806 & 0.510 \\
\hline Need for Interaction & 0.773 & 0.898 & 0.815 \\
\hline Perceived Usefulness & 0.883 & 0.919 & 0.740 \\
\hline Perceived Ease of Use & 0.640 & 0.806 & 0.581 \\
\hline
\end{tabular}

Through reliability test, three of five items for "Need for Interaction" and one of four item for "Perceived Ease of Use" were eliminated to increase reliability. And the final results of reliability test is reported in Table III. Despite of elimination, "Autonomy" and "Perceived Ease of Use" have still insufficient Cronbach's alpha coefficient. But they were not adjusted more because they have acceptable coefficient of composite reliability and AVE, and in some cases, Cronbach alpha values from 0.6 to 0.7 were deemed the lower limit of acceptability [26].

For testing validity, cross loadings table of model was used 
as reported in Table IV. Each loadings for own latent variables was relatively higher than those for other latent variables.

\section{RESUlts}

\section{A. Hypothesis test by PLS}

To test hypothesis, Smart-PLS was used as a statistical tool. Considering sample size and theoretical frame, covariance based methods like structural equation model were not proper for this research.

TABLE IV: RESULTS OF VALIDITY TEST BY CROSS LOADINGS

\begin{tabular}{|c|c|c|c|c|c|}
\hline & ISK & ATN & NI & PU & PEOU \\
\hline ISK1 & $\mathbf{0 . 8 6 6}$ & 0.368 & 0.574 & 0.595 & 0.302 \\
\hline ISK2 & $\mathbf{0 . 8 6 3}$ & 0.451 & 0.540 & 0.541 & 0.356 \\
\hline ISK3 & $\mathbf{0 . 7 6 7}$ & 0.440 & 0.496 & 0.611 & 0.551 \\
\hline ISK4 & $\mathbf{0 . 7 0 3}$ & 0.477 & 0.510 & 0.448 & 0.263 \\
\hline ISK5 & $\mathbf{0 . 8 4 1}$ & 0.457 & 0.482 & 0.563 & 0.375 \\
\hline ATN1 & 0.347 & $\mathbf{0 . 7 2 3}$ & 0.421 & 0.165 & 0.255 \\
\hline ATN2 & 0.460 & $\mathbf{0 . 7 5 3}$ & 0.357 & 0.224 & 0.277 \\
\hline ATN3 & 0.326 & $\mathbf{0 . 6 9 4}$ & 0.330 & 0.192 & 0.160 \\
\hline ATN4 & 0.399 & $\mathbf{0 . 6 8 5}$ & 0.290 & 0.240 & 0.302 \\
\hline NI1 & 0.550 & 0.428 & $\mathbf{0 . 8 9 3}$ & 0.430 & 0.358 \\
\hline NI2 & 0.608 & 0.455 & $\mathbf{0 . 9 1 2}$ & 0.503 & 0.369 \\
\hline PU1 & 0.449 & 0.197 & 0.324 & $\mathbf{0 . 8 1 9}$ & 0.529 \\
\hline PU2 & 0.619 & 0.315 & 0.586 & $\mathbf{0 . 9 1 1}$ & 0.619 \\
\hline PU3 & 0.637 & 0.202 & 0.451 & $\mathbf{0 . 8 6 1}$ & 0.613 \\
\hline PU4 & 0.633 & 0.265 & 0.386 & $\mathbf{0 . 8 4 8}$ & 0.534 \\
\hline PEOU1 & 0.328 & 0.319 & 0.312 & 0.465 & $\mathbf{0 . 7 5 6}$ \\
\hline PEOU3 & 0.426 & 0.257 & 0.370 & 0.549 & $\mathbf{0 . 8 0 8}$ \\
\hline PEOU4 & 0.296 & 0.234 & 0.230 & 0.517 & $\mathbf{0 . 7 2 1}$ \\
\hline NE: ISK
\end{tabular}

Note: ISK = Intention to Share Knowledge through Information Systems ; ATN = Autonomy; NI = Need for Interaction; PU = Perceived Usefulness; $\mathrm{PEOU}=$ Perceived Ease of Use.

Using Smart-PLS, model and hypotheses were tested. PLS doesn't provide significance of path coefficient, but it can be inferred by statistical methods like bootstrapping and jack knifing [25]. For this, bootstrapping was used with 1,000 samples from 107 responses, and significances of each path coefficient were estimated by t-value. The result is shown in Fig. 3.

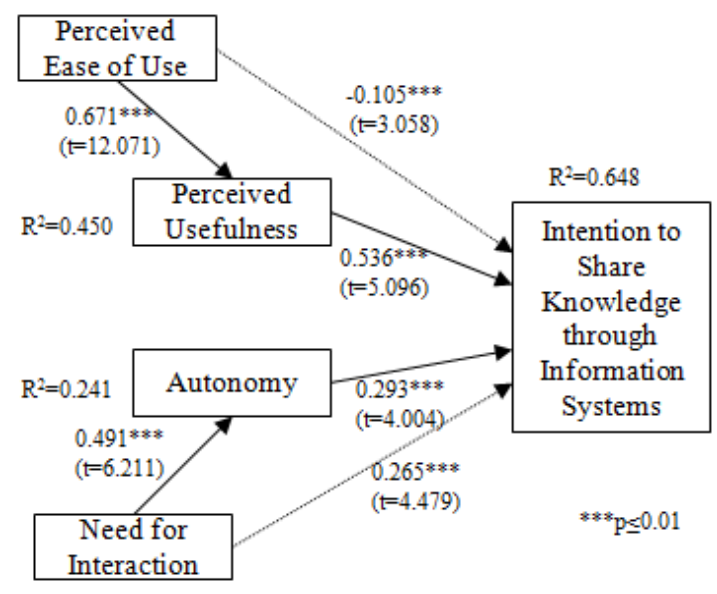

Fig. 3. Results of hypothesis test.

All relationship between constructs, assumed by hypothesis in this research, were significant at $99 \%$ confidence interval. But H2 and H5 couldn't be accepted because they had opposite effect than hypothesis.

"Perceived Ease of Use" influences "Perceived Usefulness" strongly, but it has negative effect on "Intention to Share Knowledge through Information Systems". In these days, some researches based on TAM with additional constructs, didn't assume the direct relation between "Perceived Ease of Use" and construct about intention. It can be supposed that most of on-line based IT service users are familiar with that kind of services in these days, so it can be regarded as just an antecedent of some other variables.

"Need for Interaction" has positive effect on "Intention to Share Knowledge through Information Systems". It means that information systems for knowledge sharing is not just a tool for efficiency in organization.

Another interesting findings of this research is that the weight of technology acceptance aspect and self determination aspect are similar. It can be a clue for finding alternative research model for usage of web 2.0 services.

\section{B. Comparison with Two Approaches}

This research was based on two theoretical approaches, and they were merged in this research model. Then, it's required to confirm whether the explanation power of this research model was improved than that of each single approaches.

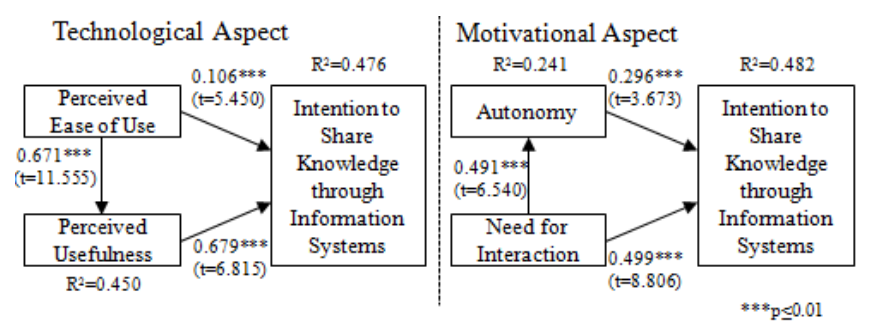

Fig. 4. Results of model comparison.

Each single approaches of both technological and motivational aspect were tested with the same methods of hypothesis test, and it's reported at Fig. 4. R-squares of both model were similar, and both of them were about 0.17 smaller than that of this research model.

\section{ANOVA Test}

Survey for this research includes 3 questions about identities of respondents; gender, place of work, and job experiences, because there are possibilities that some variables will be differed by gender, a sense of alienation for information, and level of knowledge about job. All of constructs were not differentiated by gender. "Autonomy" was significantly differentiated by job experiences, and "Intention to Share Knowledge through Information Systems" was slightly differentiated by both place of work and job experiences.

TABLE V: RESULTS FROM ANOVA

\begin{tabular}{|l|l|l|l|l|}
\hline \multirow{2}{*}{ Construct } & \multicolumn{2}{|l|}{$\begin{array}{l}\text { By place of } \\
\text { work }\end{array}$} & \multicolumn{2}{l|}{$\begin{array}{l}\text { By job } \\
\text { experiences }\end{array}$} \\
\cline { 2 - 5 } & F-value & Sig. & F-value & Sig. \\
\hline Autonomy & 0.192 & 0.662 & 6.779 & 0.011 \\
\hline $\begin{array}{l}\text { Intention to Share Knowledge } \\
\text { through Information Systems }\end{array}$ & 3.611 & 0.060 & 3.252 & 0.074 \\
\hline
\end{tabular}

\section{IMPLICATIONS AND LIMITATIONS}

This study examined that knowledge sharing through 
information system also can be adopted to TAM except for the direct relation between "Perceived Ease of Use" and intention. Another important implication of this research is that concept of self determination is also a meaningful factor for knowledge sharing through information systems with similar weight of TAM. Knowledge sharing or management systems have been regarded as technological system itself or concentrated on extrinsic rewards to promote it in many companies. But, as a result of this research, improving "Autonomy" of individuals is important task for company to activate knowledge sharing systems, as a web 2.0 service.

Another evidence of this can be found the positive effect of "Need for interaction". It can be explained that knowledge sharing can be activated with non-technological interactions between users, and interaction is a important factor to motivate individual's "Autonomy".

In these days, social network service (SNS) have been broadly used more and more. Even business field, enterprise SNS have received attention as a tool for knowledge sharing or collaboration in companies. Organizations which want to activate knowledge sharing can refer this phenomenon and the result of this research.

This study suggests some implications with theoretical framework, but it also has some limitations. First limitation is lack of generalizability. Data of survey responses were gathered from only one company because of consistency of context. But, to retain external validity, this research model should be tested under various context of web 2.0 services with data sampling from various organizations. Second, though the importance of "Autonomy" was unveiled, this research can not explain the determinants of it. Third, this research can not explain the after effect of it. In other words, this research can just explain the behavioral facet it self, and can not explain the antecedent and ultimate purpose of it. It is recommended that future researches are required to complement this research.

\section{REFERENCES}

[1] G. David, "Creating a knowledge sharing culture," Knowledge Management Magazine, vol. 2, iss. 5, 1999.

[2] R. Agarwal and E. Karahanna, "Time flies when you're having fun: Cognitive absorption and beliefs about information technology," MIS Quarterly, vol. 24, no. 4, pp. 665-694, 2000.

[3] D. Gefen, E. Karahanna, and D. Straub, "Trust and TAM in online shopping: An integrated model," MIS Quarterly, vol. 27, no. 1, pp. 51-90, 2003.

[4] P. Laurn and H. H. Lin, "Toward an understanding of the behavioral intention to use mobile banking," Computers in Human Behavior, vol. 21, pp. 873-891, 2005.

[5] T. Bhatti, "Exploring factors influencing the adoption of mobile commerce," Journal of Internet Banking and Commerce, vol. 12, no. 3, 2007

[6] T. O. Reilly, "What is web 2. 0: Design patterns and business models for the next generation of software," Communications and Strategies, no. 65 , pp. 17-37, 2007.

[7] G. W. Bock, R. W. Zmud, Y. G. Kim, and J. N. Lee, "Behavioral intention formation in knowledge sharing: Examining the roles of extrinsic motivators, social-psychological forces, and organization climate," MIS Quarterly, vol. 29, no. 1, pp.87-111, 2005.
[8] I. Ajzen, "From intention to actions: a theory of planned behavior," in Action Control: From Cognition to Behavior, J. Kuhl and J. Bechmann, Eds. Berlin, Germany: Springer-Verlag, 1985, pp. 11-39.

[9] I. Ajzen, "The theory of planned behavior," Organizational Behavior and Human Decision Precesses, vol. 50, pp. 179-211, 1991.

[10] F. D. Davis, "Perceived usefulness, perceived ease of use, and user acceptance of information technology," MIS Quarterly, vol. 13, no. 3, pp. 319-340, 1989.

[11] M. Gagne and E. L. Deci, "Self-determination theory and work motivation," Journal of Organizational Behavior, vol. 26, pp. 331-362, 2005.

[12] E. L. Deci and R. M. Ryan, "The 'what' and 'why' of goal pursuits: Human needs and the self-determination of behavior," Psychological Inquiry, vol. 11, pp. 227-268, 2000.

[13] M. S. Hagger and N. L. D. Chatzisrantis, "Integrating the theory of planned behavior and self-determination theory in health behavior: A meta-analysis," British Journal of Health Psychology, vol. 14, pp. 275-302, 2009.

[14] M. Gagne, "A model of knowledge-sharing motivation," Human Resource Management, vol. 48, no. 4, pp. 571-589, 2009.

[15] N. L. D. Chatzisarantis, M. S. Hagger, and B. Smith, "Influence of perceived autonomy support on physical activity within the theory of planned behavior," European Journal of Social Psychology, vol. 37, pp. 934-954, 2007

[16] P. A. Dabholkar and R. P. Bagozzi, "An attitudinal model of technology-based self-service: Moderation effects of consumer traits and situaltional factors," Jouranal of the Academy of Marketing Science, vol. 30, no. 3, pp. 184-201, 2002.

[17] J. M. Curran and M. L. Meuter, "Self-service technology adoption: Comparing three technologies," Journal of Services Marketing, vol. 19, iss. 2, pp. 103-113, 2005.

[18] E. L. Deci and R. Flaste, Why We Do What We Do: Understanding Self-Motivation, Penguin Books, 1996.

[19] V. Venkatesh and F. D. Davis, "A theoretical extension of the technology acceptance model: Four longitudinal field studies," Management Science, vol. 46, no. 2, pp. 186-204, 2000.

[20] J. R. Hackman and G. R. Oldham, "Motivation through the design of work: Test of a theory," Organizational Behavior and Human Performance, vol. 16, pp. 250-279, 1976.

[21] M. K. Ahuja and J. B. Thatcher, "Moving beyond intentions and toward the theory of trying: Effects of work environment and gender on post-adoption information technology use," MIS Quarterly, vol. 29, no. 3, pp. 427-459, 2005.

[22] P. A. Dabholkar, "Consumer evaluation of new technology-based self-service service options : An investigation of alternative models of service quality," International Jouarnal of Research in Marketing, vol. 13, no. 1, pp. 29-51, 1996.

[23] J. M. Feldman and J. G. Lynch, "Self-generated validity and other effect on measurement on belief, attitude, intention, and behavior," Journal of Applied Psychology, vol. 73, no. 3, pp. 421-435, 1988.

[24] P. M. Podsakoff, S. B. MacKenzie, J. Y. Lee, and N. P. Podsakoff, "Common method biases in behavioral research: A critical review of the literature and recommended remedies," Journal of Applied Psychology, vol. 88, no. 5, pp. 879-903, 2003.

[25] W. W. Chin, "How to write up and report PLS analyses," in Handbook of PLS and Marketing, V. E. Vinzi, W. W. Chin, J. Henseler, and H. Wang, Eds, Springer Verlag, 2007, ch. 28, pp. 655-690.

[26] J. F. Hair, R. E. Anderson, R. L. Tatham, and W. C. Black, Multivariate Data Analysis with Readings, $5^{\text {th }}$ edition, Prentice Hall Inc, 1998.

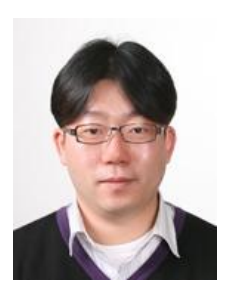

Sung Hoon Shin was born on March 4, 1975, in Seoul, Korea. He received his bachelor of educational technology from Hanyang University, Korea, 2001, and M.S. degree in advertisement from Hanyang University, Korea, 2011. He has been Ph.D. candidate of global service management in Sogang University, Korea, since 2012 . He is currently working as a general manager of business planning at internet marketing agency company eMnet, Korea. Previously, he worked as staff of e-business department at Sony Korea, Korea, from 2000 to 2001. His research interests are service science, management information system, and organizational innovation. 